Check for updates

Cite this: RSC Adv., 2017, 7, 47235

\title{
Isomeric trimesogens exhibiting modulated nematic mesophases $\dagger$
}

\begin{abstract}
Adam Al-Janabi, Richard J. Mandle (D) and John W. Goodby
Modulated nematic phases, in which the constituent molecules possess some form of superstructure in addition to the average orientational organization and lack positional order present in classical nematic phases, are of current fascination in liquid crystal research. Most of the recent focus has been on the twist-bend nematic phase. This phase exhibits phenomena that are of fundamental importance to science; the spontaneous formation of a helical pitch of nanometre scale in a fluid and the spontaneous breaking of mirror symmetry leading to the emergence of chiral domains in an achiral system. In this communication we report on the synthesis of two liquid-crystalline trimesogens whose structures are an extension of the known dimeric material CB6OCB. One material $\left(A 6_{3}\right)$ exhibits a nematic phase with a twist-bend modulation ( $\mathrm{N}_{\mathrm{TB}}$ phase), whereas a structurally isomeric material $\left(\mathrm{B}_{3}\right)$ exhibits an unusual nematic like mesophase which we believe is a candidate for being a new form of modulated nematic. Whereas the properties of dimeric LCs are somewhat indifferent to chemical composition, the stark difference in behaviour between the two materials herein shows that oligomers may exhibit an unexpected sensitivity to molecular structure.
\end{abstract}

Received 15th September 2017 Accepted 3rd October 2017

DOI: 10.1039/c7ra10261e

rsc.li/rsc-advances
Relatively little is known about the relationship between the twist-bend phase and molecular structure within the context of oligomesogenic materials, with only a handful of examples known..$^{33-36,40,41}$ One limitation to developing such a relationship is the difficulty in preparing higher oligomers. Herein we present a simple synthetic route to two isomeric trimesogens, shown in Schemes 1 and 2, which could easily be expanded to give further examples of higher oligomers with homologous structures. Examination of these two materials by POM, DSC and SAXS reveals significant differences in phase behaviour and properties.

\section{Experimental}

In our previous attempt to synthesis $\mathbf{A 6}_{\mathbf{3}}$ we were unable to cleave the benzyl ether without accompanying nitrile reduction, $^{\mathbf{4 0}}$ in the present work we circumvented this issue by moving to the use of a tert butyldimethylsilyl (TBDMS) protecting group. The phenol group of the intermediate i1, synthesis reported in,$^{\mathbf{4 0}}$ was protected with a TBDMS group and subsequent hydrogenation saturated the alkyne and removed the benzyl ether to afford i3. Mitsunobu etherification with i4 gave i5; cleavage of the TBDMS group was achieved using TBAF. Etherification of $\mathbf{i 6}$ with $\mathbf{i} 7$ afforded the trimesogen $\mathbf{A 6}_{\mathbf{3}}$.

The trimesogen $\mathbf{B 6}_{3}$, an isomer of $\mathbf{A 6}_{\mathbf{3}}$, was prepared via Mitsunobu etherification of $\mathbf{i} 7$ and $\mathbf{i 8}$ as shown in Scheme 2. Synthetic details, chemical characterisation and details of instrumentation used are given in the $\mathrm{ESI}^{\dagger}$ to this communication; both trimesogenic materials were obtained in high purity $\left(99.4 \%\right.$ for $\mathbf{A 6}_{3}$ and $99.7 \%$ for $\mathbf{B 6}_{3}$ ) as evidenced by HPLC.
Department of Chemistry, University of York, UK. E-mail: Richard.Mandle@york.ac.uk $\dagger$ Electronic supplementary information (ESI) available. See DOI: 10.1039/c7ra10261e 
a)

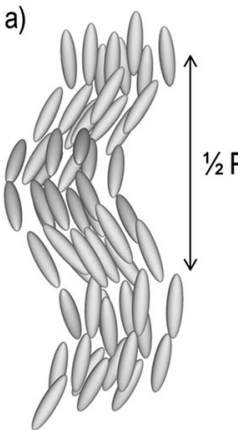

b)

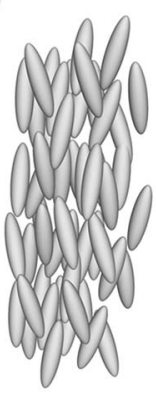

c)

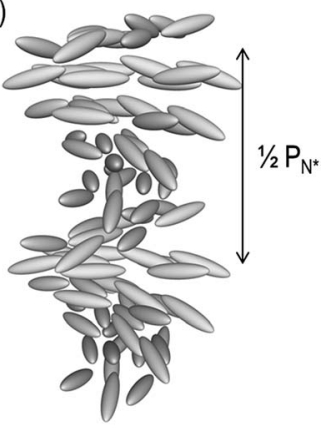

Fig. 1 Local structures and director arrangement in (a) the helicoidal twist-bend phase, (b) the uniaxial nematic phase, and (c) the chiral nematic phase. Note that the pitch depicted in (a) is much smaller than that of (c); the former being $\sim 10 \mathrm{~nm}$ while the latter can be over $1 \mu \mathrm{m}$ and even into the millimetre to meter range.
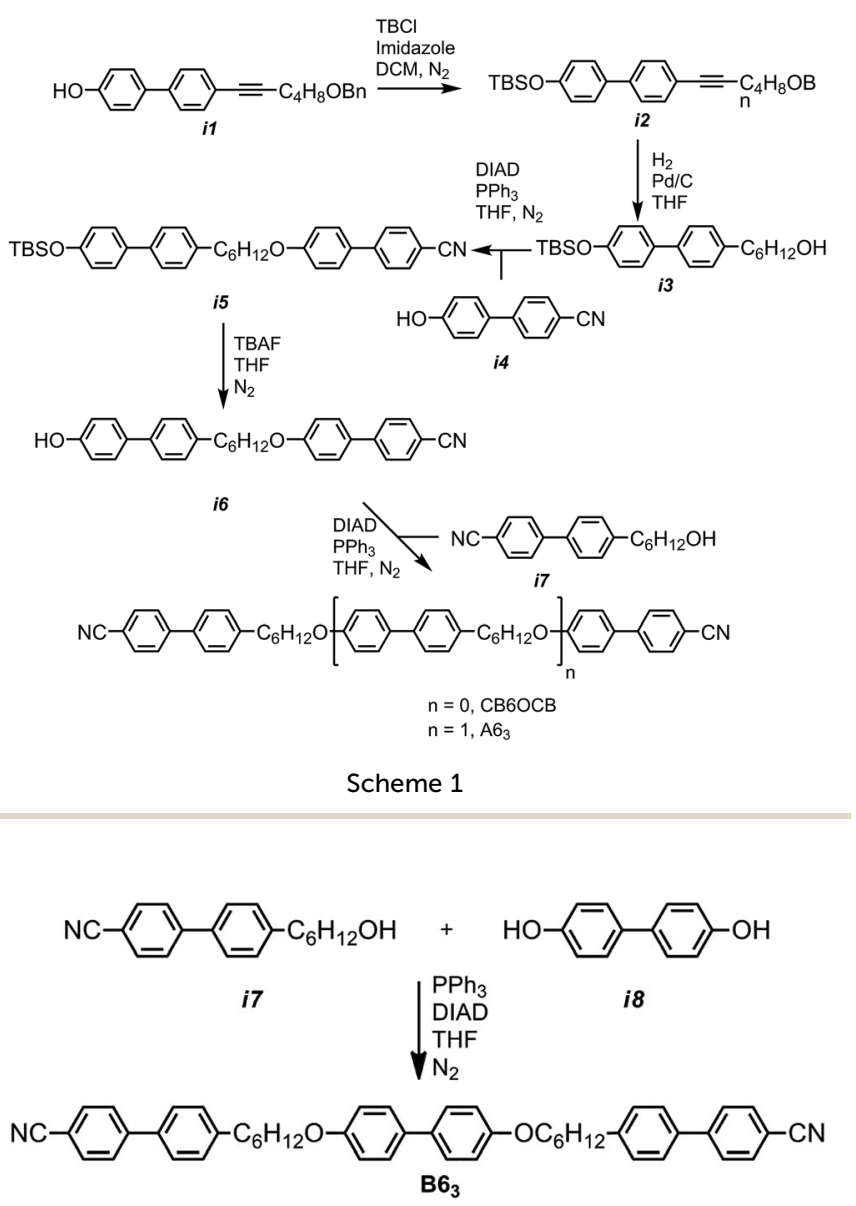

Scheme 2

\section{Results and discussion}

The transition temperatures of both $\mathbf{A 6}_{\mathbf{3}}$ and $\mathbf{B 6}_{\mathbf{3}}$ were determined using a combination of polarized optical microscopy (POM), differential scanning calorimetry (DSC) and small angle X-ray scattering (SAXS). Transition temperatures and associated enthalpies of transition for each material are presented in Table 1.

The trimesogen $\mathbf{A 6}_{\mathbf{3}}$ can be envisaged as an extension of the well-known liquid-crystalline dimer CB6OCB (Cr $102 \mathrm{~N}_{\mathrm{TB}}$ $110.5 \mathrm{~N} 154.2$ Iso); it is unsurprising therefore that this material mirrors the behaviour of the parent compound and exhibits nematic and twist-bend phases, although we note that the trimesogen $\left(\mathbf{A 6}_{\mathbf{3}}\right)$ has significantly higher melting points and transition temperatures than the parent (CB6OCB), while the associated enthalpy associated with the $\mathrm{N}-\mathrm{N}_{\mathrm{TB}}$ phase transition is an order of magnitude larger in $\mathbf{A 6}_{\mathbf{3}}$. The identification of the nematic phase was trivial based on its characteristic schlieren texture (Fig. 2a), high fluidity, Brownian motion, and diffuse scattering of X-rays at small angles (Fig. 2d and SI-7†). With further cooling a transition into the twist-bend phase occurred; regions exhibiting a schlieren texture in the nematic phase exhibited a "blocky" texture (Fig. 2b), planar aligned regions transformed into the rope texture (Fig. 2c) although homeotropic regions remained optically extinct. When the rope texture was annealed for 5 minutes at a constant temperature of $125^{\circ} \mathrm{C}$ we observed striations forming at an angle of $\sim 30^{\circ}$ to the 'length' of the rope; the possibility for the formation of fibre-like structures in the $\mathrm{N}_{\mathrm{TB}}$ has been noted previously ${ }^{42}$ and recently demonstrated to have a "fish-bone" like structure from SEM imaging of photopolymerised twist-bend dimers. ${ }^{43}$

When studied by SAXS the $\mathrm{N}_{\mathrm{TB}}$ phase of $\mathbf{A 6}_{\mathbf{3}}$ exhibited a diffuse scattering at small angles (Fig. 2e). The small angle scattering peak had a $d$-spacing value of $14.1 \AA$ which was considered as a first approximation to be roughly $1 / 3$ of the molecular length. DFT (B3LYP/6-31G(d)) calculations show that if the two outer mesogenic units are trans to each other then the molecular length is $43.5 \AA$ compared with a value of $39 \AA$ in the comparable cis geometry, however this neglects the flexibility inherent in such systems and is best considered as an approximation. The $d$-spacing values in both phases, taken in conjunction with the calculated molecular lengths, indicate the sub-units of the trimesogen behave essentially as free entities in both phases rather than the trimesogen behaving as one large 'rod-like' molecule.

As mentioned briefly, the use of a single conformer neglects the inherent flexibility afforded by the hexyloxy spacer, present in both materials. Using fully relaxed scans (at the DFT (B3LYP/ 6-31G(d)) level in Gaussian G09 revision e01) we studied a 1/2 fragment of both trimers. We allow each dihedral shown in Fig. 3 a to rotate in $10^{\circ} \mathrm{C}$ steps, giving plots of conformer energy as a function of each individual angle. For the 2nd dihedral we observe the gauche states to be lower in energy than the trans form $\left(\Delta E, 0.6 \mathrm{~kJ} \mathrm{~mol}^{-1}\right)$, for the other dihedrals the trans form is lower than gauche by $2-6 \mathrm{~kJ} \mathrm{~mol}^{-1}$. While calculation of the full conformer distribution for both materials is too computationally expensive to be feasible, even using the RIS approximation and semi-empirical methods, the present study illustrates the flexibility inherent to these systems.

Given the similarities in molecular structure it had been anticipated that $\mathbf{B 6}_{\mathbf{3}}$ would exhibit similar transition temperatures and phase behaviour to $\mathbf{A 6}_{3}$. $\mathbf{B 6}_{\mathbf{3}}$ exhibits lower transition temperatures than $\mathbf{A 6}_{\mathbf{3}}$, with identification of the nematic phase being as described previously. Upon cooling into the next phase $\left(\mathrm{N}_{\mathrm{X}}\right)$ a series of unusual optical textures were observed, which we 
Table 1 Transition temperatures and associated enthalpies of the isomeric trimesogens $\mathrm{A}_{3}$ and $\mathrm{B} 6_{3}$ as determined using DSC at a heat/ $\mathrm{cool}$ rate of $10{ }^{\circ} \mathrm{C}$. Note, presented values are the average of 3 cycles

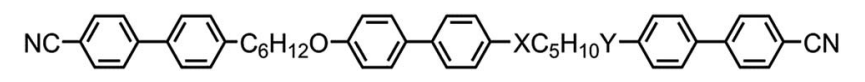

\begin{tabular}{llllrlrr}
\hline $\mathrm{Cpd}$ & $\mathrm{X}$ & $\mathrm{Y}$ & & $\mathrm{MP}$ & $\mathrm{N}_{\mathrm{X}}-\mathrm{N}$ & $\mathrm{N}_{\mathrm{TB}}-\mathrm{N}$ & $\mathrm{N}-\mathrm{IsO}$ \\
\hline $\mathbf{A 6}_{3}$ & $-\mathrm{CH}_{2}-$ & $-\mathrm{O}-$ & $T\left({ }^{\circ} \mathrm{C}\right)$ & 140.9 & - & 133.3 & 170.9 \\
& & & $\Delta H\left[\mathrm{~kJ} \mathrm{~mol}^{-1}\right]$ & 30.0 & - & 1.0 & 2.0 \\
$\mathbf{B 6}_{3}$ & $-\mathrm{O}-$ & $-\mathrm{CH}_{2}-$ & $T\left({ }^{\circ} \mathrm{C}\right)$ & 118.4 & 116.4 & - & 156.7 \\
& & & $\Delta H\left[\mathrm{~kJ} \mathrm{~mol}^{-1}\right]$ & 16.7 & 1.4 & - & 2.0 \\
& & & & & & &
\end{tabular}

describe as follows. On an untreated glass slide we observed that regions exhibiting a schlieren texture initially take on a patchy appearance at the phase transition into the $\mathrm{N}_{\mathrm{X}}$ phase before then forming a nondescript, sand-like texture (Fig. 4a-c). We performed SAXS on $\mathbf{B 6}_{3}$, collecting frames on cooling in $1.2{ }^{\circ} \mathrm{C}$ intervals from the clearing point until the sample crystallised at $\sim 103{ }^{\circ} \mathrm{C}$. The nematic nature of both phases, hinted at by the small enthalpy associated with the transition, was confirmed by the diffuse small angle peak in SAXS (2D patterns in Fig. 4d and e, data in Fig. 4f-h). Both the onset temperature and the enthalpy associated with the first order $\mathrm{N}-\mathrm{N}_{\mathrm{X}}$ transition were found to be invariant with the heat/cool rate employed in DSC studies unlike for the dimer CB11CB where the $\mathrm{N}_{\mathrm{TB}}-\mathrm{N}$ transition appears almost second order and resolves into a small first order peak with varying scan rate, ${ }^{45}$ although this phenomenon is not repeated by either material in this present work.
Radial integration of each SAXS pattern gave scattered intensity as a function of $Q$; fitting the raw scattering data with a Lorentzian function gave the $d$-spacings of the small- (001) and wide- (100) angle peaks (Fig. 4f), which we find to be temperature invariant. The small-angle scattering peak has a $d$ spacing of $\sim 14 \AA$ in both phases; we do not observe any scattering events at smaller angles up to the limit of our experimental setup at $\sim 100 \AA$. We obtain molecular lengths at the DFT (B3LYP/6-31G(d)) level; as with $\mathbf{A 6}_{3}$ we find that if the two outer mesogenic units are trans to each other the molecular length is $42.7 \AA$ compared with a value of $38.5 \AA$ in the comparable cis geometry, i.e. the $d$-spacing of the small angle peak corresponds to $\sim 1 / 3$ of the molecular length. Although this neglects the flexibility of $\mathbf{B 6}_{3}$, but the present results indicate that, as with $\mathbf{A 6}_{3}$, the trimesogen does not behave as one large 'rod-like' molecule. The correlation lengths were determined from the FWHM of each peak; whereas the correlation length parallel to the director decreases slightly at the $\mathrm{N}-\mathrm{N}_{\mathrm{X}}$ phase transition the perpendicular correlation length increases marginally, however we find the magnitude of both correlation lengths is consistent with a nematic-like phase. Lastly, we plot the maximum intensity of both small- and wide-angle peaks as a function of temperature, we observe that there is a decrease in the intensity small-angle scattering at the $\mathrm{N}-\mathrm{N}_{\mathrm{X}}$ transition however there is a corresponding increase in the intensity wideangle scattering.

Good quality planar alignment was achieved for both compounds when filled into cells with a buffed antiparallel alignment layer (purchased from Instec thickness $\sim 5 \mu \mathrm{m}$ ). The
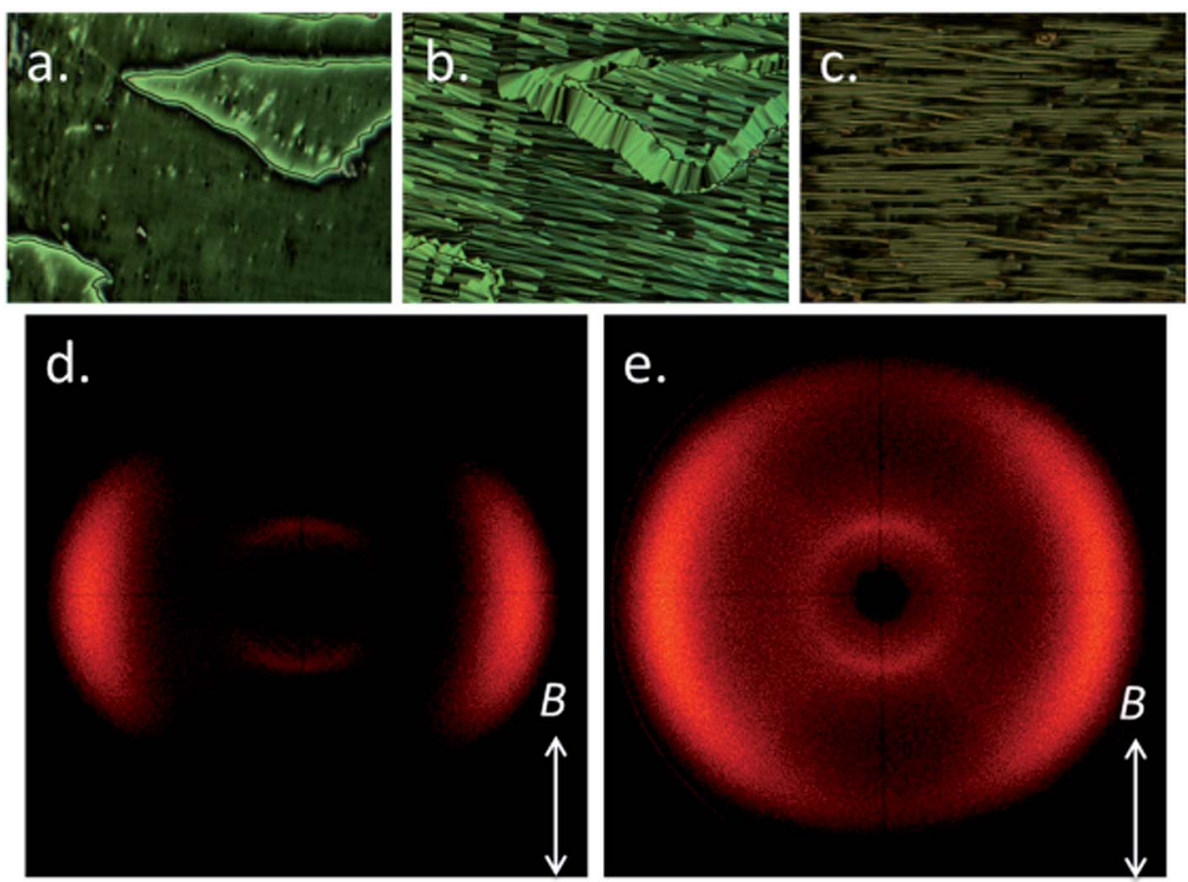

Fig. 2 Characterisation of $\mathrm{A}_{3}$ : photomicrographs ( $\times 100$, crossed polarisers) of (a) the nematic phase of $A 6_{3}$ at $135^{\circ} \mathrm{C}$; (b) the same region as a cooled into the twist-bend phase at $128^{\circ} \mathrm{C}$; (c) the rope texture of the twist-bend phase at $128^{\circ} \mathrm{C}$; (d) $2 \mathrm{D}$ SAXS pattern for the nematic phase of $\mathrm{A} 6_{3}$ at $145^{\circ} \mathrm{C}$; (e) $2 \mathrm{D} \mathrm{SAXS}$ pattern for the $\mathrm{N}_{\mathrm{TB}}$ phase of $\mathrm{A} 6_{3}$ at $125^{\circ} \mathrm{C}$ - note due to a tendency for sample crystallisation the exposure time in the $\mathrm{N}_{\text {TB }}$ phase was shorter (30 seconds vs. 300 seconds) leading to a poorer signal-to-noise ratio. 


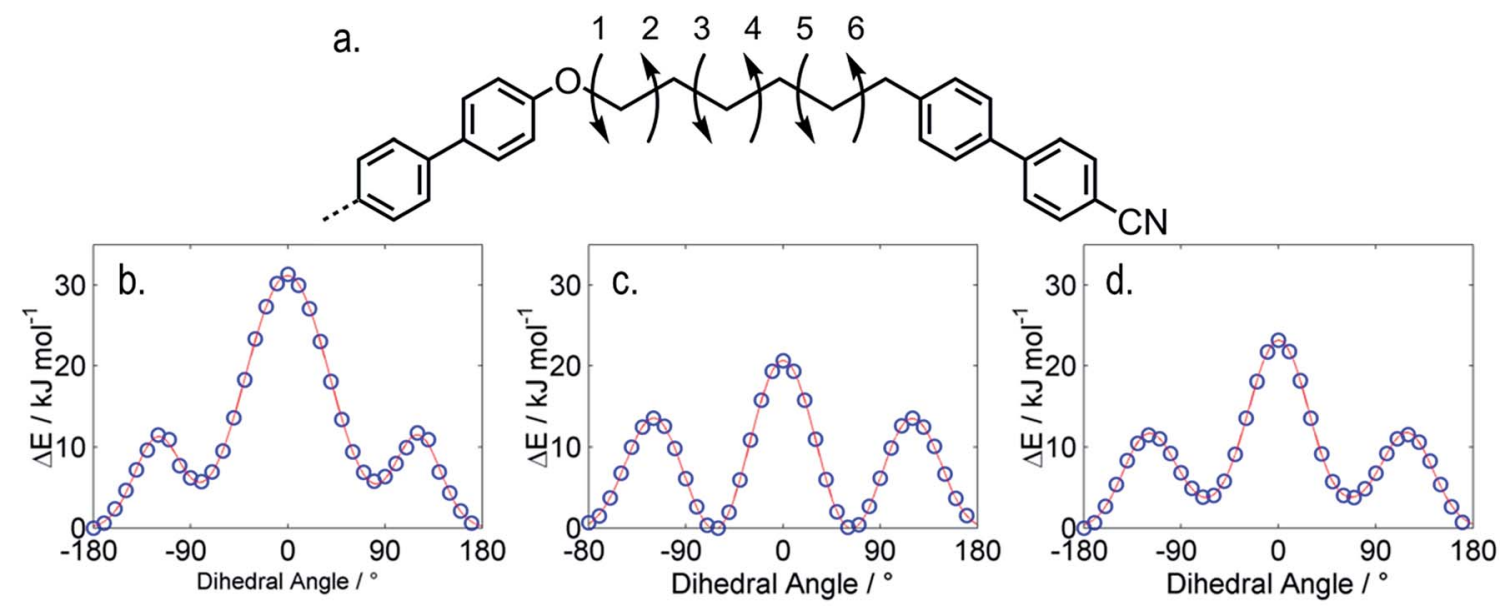
$\begin{array}{llllll}1 & 2 & 3 & 4 & 5 & 6\end{array}$
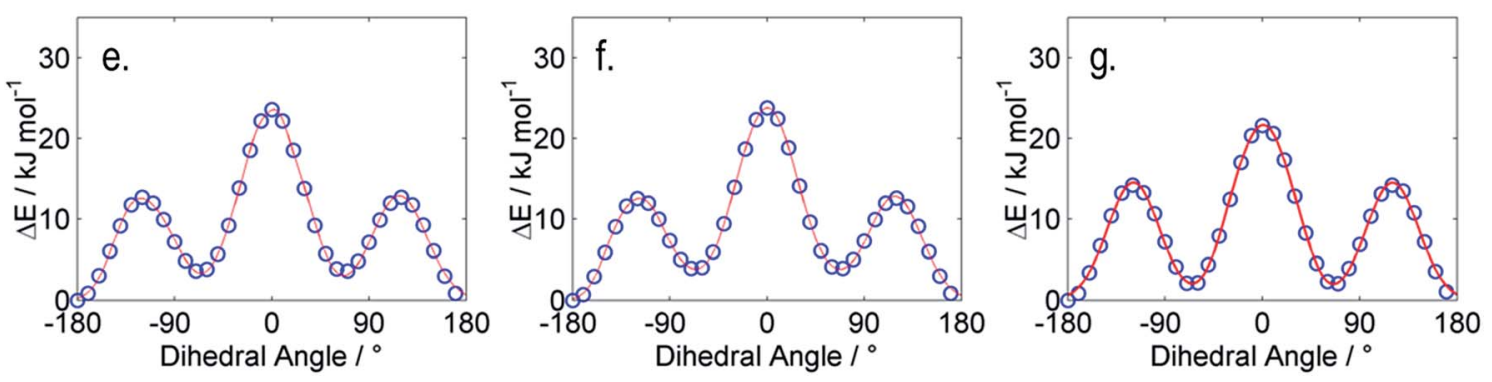

Fig. 3 The dihedrals shown in (a) were allowed to rotate in $10{ }^{\circ} \mathrm{C}$ steps using fully relaxed scans at the B3LPY/6-31G(d) level of DFT as implemented in Gaussian G09 revision e.01,44 the plots $(\mathrm{b}-\mathrm{g})$ show the energy of as a function of each dihedral relative to that of the lowest energy conformer; (b) dihedral 1; (c) dihedral 2; (d) dihedral 3; (e) dihedral 4; (f) dihedral 5; (g) dihedral 6.
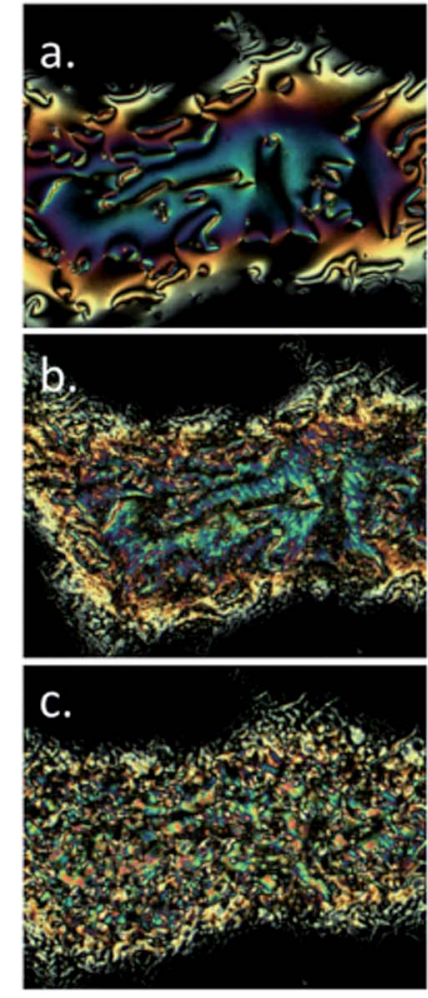
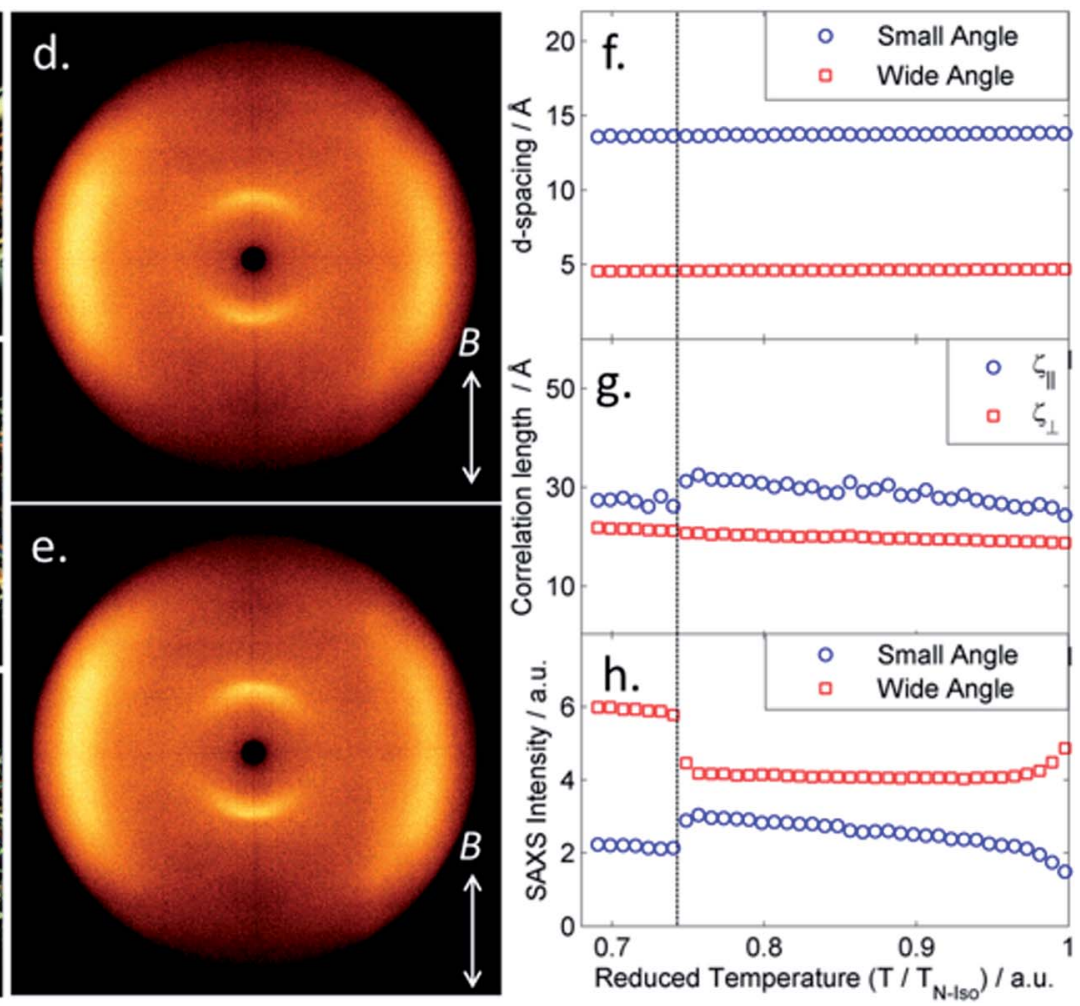

Fig. 4 Characterisation of $\mathrm{B}_{3}$ : photomicrographs $\left(\times 100\right.$, crossed polarisers) of (a) the nematic phase at $145^{\circ} \mathrm{C}$; (b) the transition into the $\mathrm{N}_{x}$ phase at $118.5^{\circ} \mathrm{C}$; (c) the $\mathrm{N}_{X}$ phase at $116^{\circ} \mathrm{C}$; (d) $2 \mathrm{D}$ SAXS pattern of the nematic phase at $137^{\circ} \mathrm{C}$; (e) $2 \mathrm{D}$ SAXS pattern of the $\mathrm{N}_{X}$ phase at $111{ }^{\circ} \mathrm{C}$; (f) plot of the $d$-spacing of the 001 (small angle) and 100 (wide angle) peaks in SAXS as a function of reduced temperature; (g) plot of the correlation length parallel $\left(\zeta_{\|}\right)$and perpendicular $\left(\zeta_{\perp}\right)$ to the director as a function of reduced temperature; (h) plot of the intensity (arbitrary units) of the small- and wide-peaks during SAXS as a function of reduced temperature. In plots $(f-h)$ the dashed line corresponds to the $\mathrm{N}-\mathrm{N}_{\mathrm{X}}$ phase transition. 

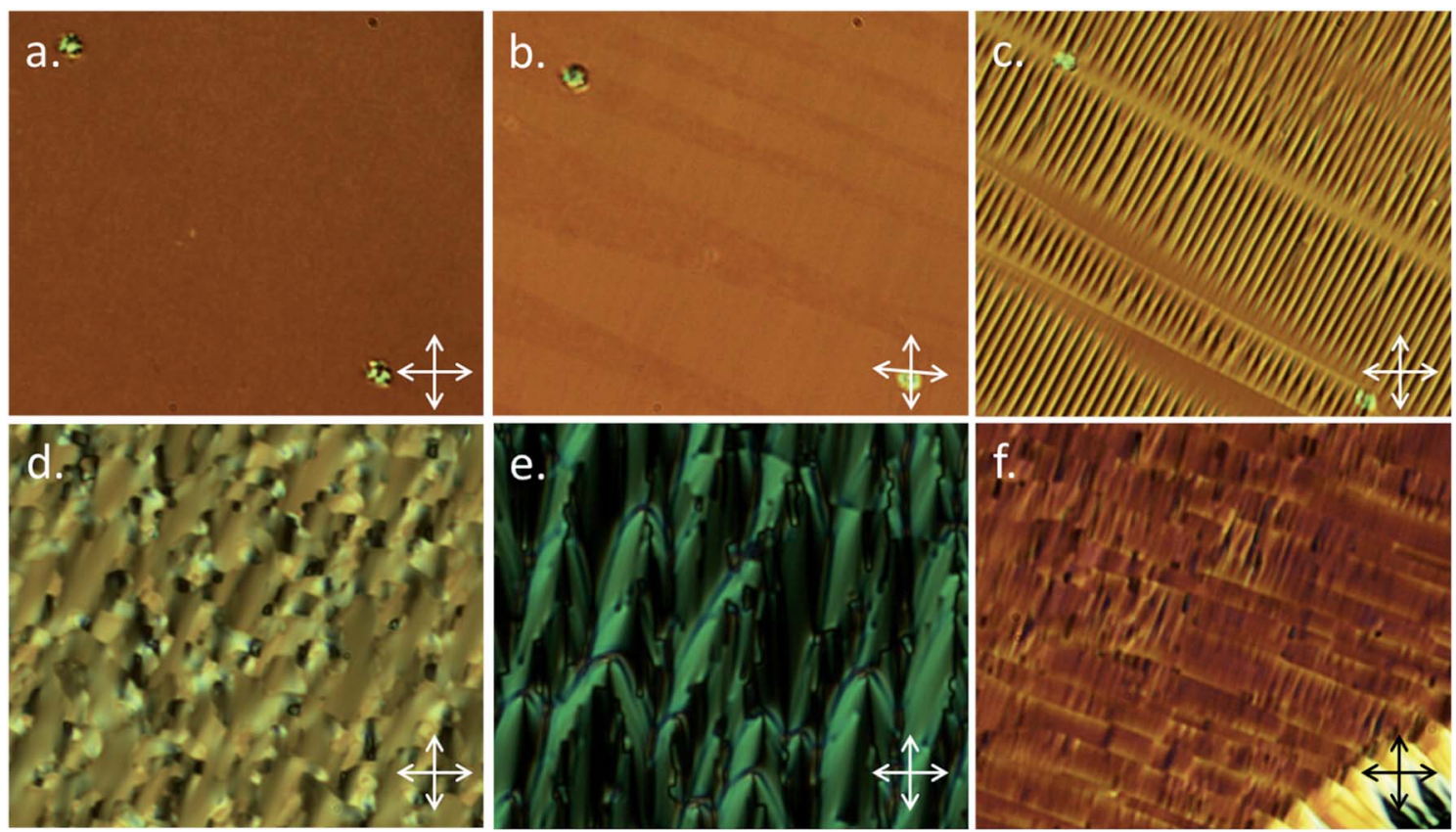

Fig. 5 Optical textures $\left(\times 100\right.$, crossed polarisers) of $A 6_{3}(a-c)$ and $B 6_{3}(d-f)$ in cells treated to give planar alignment: (a) the uniform planar texture of the nematic phase of $\mathrm{A}_{3}$ at $145^{\circ} \mathrm{C}$; (b) the same region as (a) cooled into the $\mathrm{N}_{\mathrm{TB}}$ phase (right) at $133^{\circ} \mathrm{C}$, note the slightly uncrossed polarisers to aid visualisation of the different handed $\mathrm{N}_{\text {ТВ }}$ domains; (c) the same region as (b) cooled further into the $\mathrm{N}_{\text {TВ }}$ phase showing the rope texture forming; (d) a block-like texture in the $\mathrm{N}_{x}$ phase of $\mathrm{B}_{3}$ at $116^{\circ} \mathrm{C}$ cooling from a well-aligned planar region; (e) further cooling or annealing of the block texture leads to parabolic-like defects in the $\mathrm{N}_{x}$ phase of $\mathrm{B} 6_{3}$; (f) a region of the $\mathrm{N}_{\mathrm{X}}$ phase of $\mathrm{B} 6_{3}$ at $115^{\circ} \mathrm{C}$ exhibiting a similar texture to that of the $\mathrm{N}_{\text {TВ }}$ phase in (b), however the rope-texture (c) does not form.

behaviour of $\mathbf{A 6}_{3}$ was in keeping with our studies on CB11CB in the same confined geometry; the well aligned planar texture in the nematic phase (Fig. 5a) gives way to domains of differing handedness at the $\mathrm{N}_{\mathrm{TB}}$ transition (Fig. $5 \mathrm{~b}$ ), with further cooling giving a rope-like texture perpendicular to the rubbing direction of the cell (Fig. 5c). This behaviour is typical for the $\mathrm{N}_{\mathrm{TB}}$ phase. The isomeric trimesogen $\mathbf{B 6}_{3}$ also afforded a well aligned planar texture in the nematic phase, however with further cooling a blocky texture emerged (Fig. 5d) which slowly transformed into a parabolic texture (Fig. 5e). Some regions formed a quasiplanar texture featuring regions with different handed domains (Fig. 5f); this is reminiscent of the twist-bend phase, however, this texture in the twist-bend phase gives way to the rope texture (Fig. $5 \mathrm{~b}$ and c) yet in the $\mathrm{N}_{\mathrm{X}}$ phase of $\mathbf{B 6}_{3}$ we did not observe a fully-fledged rope texture. Whereas the optical texture of the $\mathrm{N}_{\text {Тв }}$ phase changes significantly with cooling, the changes in the optical texture of the $\mathrm{N}_{\mathrm{X}}$ phase exhibited by $\mathbf{B 6}_{3}$ are less pronounced.

We next subjected a sample of $\mathbf{B 6}_{\mathbf{3}}$ to slow cooling across the $\mathrm{N}-\mathrm{N}_{\mathrm{X}}$ phase transition in order to obtain superior optical textures, with a view to ruling out this phase as simply being a twist-bend nematic. The typical schlieren texture of the nematic phase (Fig. 6a) is made up of disclinations, following the transition into the $\mathrm{N}_{\mathrm{X}}$ phase these lines become broken and fractal (Fig. 6b). At the $\mathrm{N}-\mathrm{N}_{\mathrm{TB}}$ phase transition planar aligned regions adopt a blocky texture (for example Fig. $2 b$ ), whereas at the $\mathrm{N}-\mathrm{N}_{\mathrm{X}}$ a curved, fractal texture is obtained (Fig. 6b).

Additionally the $\mathrm{N}_{\mathrm{TB}}$ phase exhibits focal-conic defects, whereas none have been observed in the optical textures of the
$\mathrm{N}_{\mathrm{X}}$ phase of $\mathbf{B 6}_{3}$. With further cooling there is a significant change in the birefringence of the sample, with long curved domains appearing (Fig. 6c). The sample could easily be sheared to give a fairly uniform homeotropic texture (Fig. 6d). Uniform homeotropic alignment of both the nematic and $N_{X}$ phases of $\mathbf{B 6}_{3}$ was realised using glass slides treated with piranha solution (30\% hydrogen peroxide and 95\% sulphuric acid in a $1: 3$ ratio); subsequent conoscopy demonstrates the $\mathrm{N}_{\mathrm{X}}$ phase to be optically uniaxial (Fig. 6e) and, after inserting a 1/4 waveplate into the microscope, optically positive (Fig. 6f). Lastly, a contact preparation between the two materials demonstrated them to be immiscible - while this may be due to simple chemical immiscibility we have observed previously that dimers of different structure and average gross bend tend to be miscible,$^{38}$ thus, this result adds weight to the assignment of the $\mathrm{N}_{\mathrm{X}}$ phase as being something other than a 'normal' $\mathrm{N}_{\text {ТВ }}$ phase. Conoscopy gives crucial information about the local structure of the $\mathrm{N}_{\mathrm{X}}$ phase; firstly as this phase is optically uniaxial it is implied that the modulation period $\left(P_{\text {mod }}\right)$ is much shorter than the wavelength of visible light $\left(P_{\bmod } \ll \lambda\right)$. As the phase is optically positive the molecules must be tilted away from the director by less than the magic angle. Although the twist-bend phase would satisfy both of these observations, as well as the diffuse nematic-like SAXS patterns, the optical textures observed for $\mathbf{B 6}_{3}$ are sufficiently distinct from those of $\mathbf{A 6}_{3}$ and other twist-bend materials to suggest this is not the case.

If the $\mathrm{N}_{\mathrm{X}}$ phase has a structure with modulation of electron density (e.g. SmA, splay-bend nematic) Bragg scattering should be observed; as this has not been observed it raises two 
possibilities for the structure of the $\mathrm{N}_{\mathrm{X}}$ phase exhibited by $\mathbf{B 6}_{3}$ : the modulation period is large enough that the corresponding Bragg scattering peak (and its harmonics) occur at larger $d$ spacings than those we can observe using our SAXS setup $(\sim 100 \AA)$. Alternatively, if there is no modulation of electron density associated with the $\mathrm{N}_{\mathrm{X}}$ phase (similar to that observed for the $\mathrm{N}_{\mathrm{TB}}$ ) then non-resonant X-ray experiments are blind to the modulation period. We note the possibility that the structure may have no modulation whatsoever; we consider this unlikely given the changes in optical textures. The change in SAXS peak intensity as well as the associated enthalpy of transition of the two materials are comparable, though not identical, for both materials and to previously reported trimesogens exhibiting the twist-bend phase. ${ }^{34,36}$

In the original work on the CBnCB materials the phase now identified as being $\mathrm{N}_{\mathrm{TB}}$ was often identified as being smectic, presumably because of its smectic-like optical textures resulting from its periodic structure. We note that the trimesogen shown in Fig. 7, described 20 years ago by both Zuev and Imrie in separate publications, is reported as exhibiting nematic and

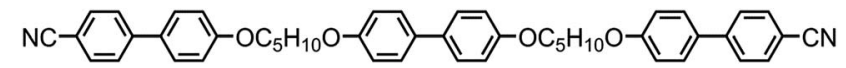

Fig. 7 The chemical structure of the liquid-crystalline trimesogen reported separately by Zuev ${ }^{46}$ and Imrie. ${ }^{47}$ Transition temperatures $\left({ }^{\circ} \mathrm{C}\right)$ reported by Imrie and Luckhurst are Cr 173 (SmA 124) N 215 Iso. Liq.

smectic phases. Given the similarity of the molecular structure of this material to $\mathbf{A 6}_{\mathbf{3}}$ and $\mathbf{B 6}_{\mathbf{3}}$ a thorough re-examination of such materials may be warranted.

\section{Conclusions}

Two trimesogenic liquid-crystalline materials - both isomers of one another - have been prepared and characterised. The method used to prepare these materials should finally allow access to chemically stable oligomeric materials of any given length, and polydispersity approaching unity. One material $\left(\mathbf{A 6}_{3}\right)$ exhibits nematic and twist-bend mesophases, however its counterpart material $\left(\mathbf{B 6}_{\mathbf{3}}\right)$ exhibits a nematic-like mesophase
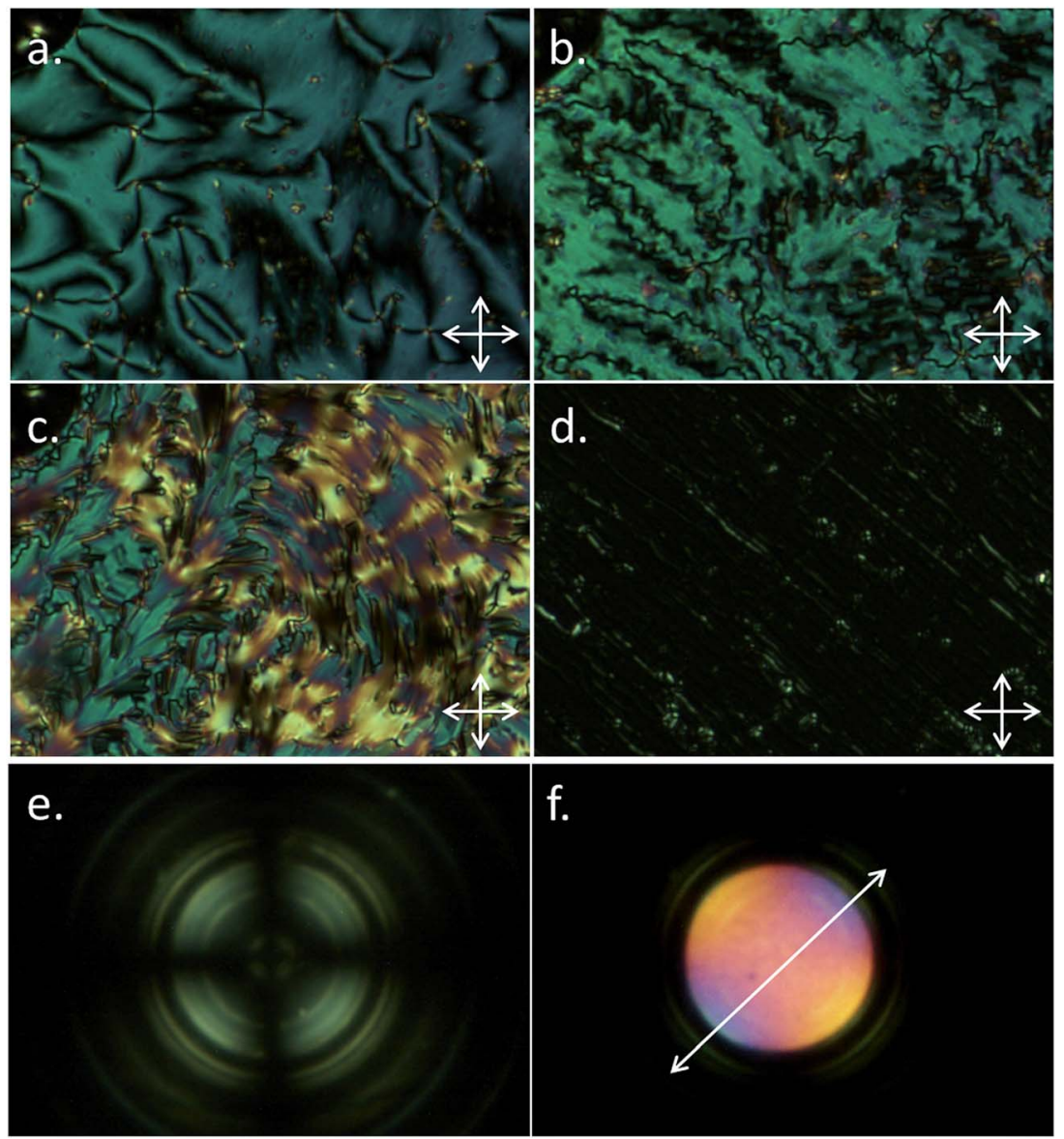

Fig. 6 Photomicrographs $\left(\times 100\right.$, crossed polarisers) of (a) the schlieren texture of the nematic phase at $140{ }^{\circ} \mathrm{C}$; (b) the transition into the $\mathrm{N}_{\times}$ phase at $118.5^{\circ} \mathrm{C}$; (c) the natural texture of the $\mathrm{N}_{x}$ phase at $115^{\circ} \mathrm{C}$; (d) the sample was sheared, giving an optically extinct texture with some birefringent streaks. All four photomicrographs are of the same region of the sample, prepared on untreated glass slides (see the sample-air interface, top left corner). (e) Photomicrograph of the conoscopic figure of the $\mathrm{N}_{x}$ phase of $\mathrm{B}_{3}$, demonstrating the phase to be optically uniaxial; (f) insertion of a $1 / 4$ waveplate into the microscope shows the phase to be optically positive, the slow axis of the waveplate is indicated by the white double headed arrow. 
structure for which we have not been able to provide a definitive identity. Studies to date point to a modulated nematic phase, with a small modulation period, and although it is possible that the observed ' $\mathrm{N}_{\mathrm{X}}$ ' phase may be simply a twist-bend nematic, the potential immiscibility of the two materials as well as the remarkably different optical textures suggest this is not the case and thus a new liquid crystal phase may be a possibility that warrants further study on this material, its analogues and higher oligomeric homologues.

\section{Conflicts of interest}

There are no conflicts of interest to declare.

\section{Acknowledgements}

RJM would like to thank the Department of Chemistry at the University of York for funding a research placement for AAJ. The authors thank the EPSRC for funding the SAXS setup used in this work via grant EP/K039660/1.

\section{References}

1 D. A. Paterson, J. Xiang, G. Singh, R. Walker, D. M. AgraKooijman, A. Martinez-Felipe, M. Gan, J. M. D. Storey, S. Kumar, O. D. Lavrentovich and C. T. Imrie, J. Am. Chem. Soc., 2016, 138, 5283-5289.

2 Z. P. Zhang, V. P. Panov, M. Nagaraj, R. J. Mandle, J. W. Goodby, G. R. Luckhurst, J. C. Jones and H. F. Gleeson, J. Mater. Chem. C, 2015, 3, 10007-10016.

3 N. Sebastian, D. O. Lopez, B. Robles-Hernandez, M. R. de la Fuente, J. Salud, M. A. Perez-Jubindo, D. A. Dunmur, G. R. Luckhurst and D. J. Jackson, Phys. Chem. Chem. Phys., 2014, 16, 21391-21406.

4 D. Chen, M. Nakata, R. Shao, M. R. Tuchband, M. Shuai, U. Baumeister, W. Weissflog, D. M. Walba, M. A. Glaser, J. E. Maclennan and N. A. Clark, Phys. Rev. E: Stat., Nonlinear, Soft Matter Phys., 2014, 89, 022506.

5 A. Zep, S. Aya, K. Aihara, K. Ema, D. Pociecha, K. Madrak, P. Bernatowicz, H. Takezoe and E. Gorecka, J. Mater. Chem. C, 2013, 1, 46-49.

6 D. Chen, J. H. Porada, J. B. Hooper, A. Klittnick, Y. Shen, M. R. Tuchband, E. Korblova, D. Bedrov, D. M. Walba, M. A. Glaser, J. E. Maclennan and N. A. Clark, Proc. Natl. Acad. Sci. U. S. A., 2013, 110, 15931-15936.

7 V. Borshch, Y. K. Kim, J. Xiang, M. Gao, A. Jakli, V. P. Panov, J. K. Vij, C. T. Imrie, M. G. Tamba, G. H. Mehl and O. D. Lavrentovich, Nat. Commun., 2013, 4, 2635.

8 K. Adlem, M. Copic, G. R. Luckhurst, A. Mertelj, O. Parri, R. M. Richardson, B. D. Snow, B. A. Timimi, R. P. Tuffin and D. Wilkes, Phys. Rev. E: Stat., Nonlinear, Soft Matter Phys., 2013, 88.

9 P. A. Henderson and C. T. Imrie, Liq. Cryst., 2011, 38, 14071414.

10 M. Cestari, S. Diez-Berart, D. A. Dunmur, A. Ferrarini, M. R. de la Fuente, D. J. Jackson, D. O. Lopez, G. R. Luckhurst, M. A. Perez-Jubindo, R. M. Richardson,
J. Salud, B. A. Timimi and H. Zimmermann, Phys. Rev. E: Stat., Nonlinear, Soft Matter Phys., 2011, 84, 031704.

11 M. Sepelj, A. Lesac, U. Baumeister, S. Diele, H. L. Nguyen and D. W. Bruce, J. Mater. Chem., 2007, 17, 1154-1165.

12 M. Sepelj, A. Lesac, U. Baumeister, S. Diele, D. W. Bruce and Z. Hamersak, Chem. Mater., 2006, 18, 2050-2058.

13 I. Dozov, Europhys. Lett., 2001, 56, 247-253.

14 C. Zhu, M. R. Tuchband, A. Young, M. Shuai, A. Scarbrough,

D. M. Walba, J. E. Maclennan, C. Wang, A. Hexemer and

N. A. Clark, Phys. Rev. Lett., 2016, 116, 147803.

15 J. W. Emsley, P. Lesot, G. R. Luckhurst, A. Meddour and D. Merlet, Phys. Rev. E: Stat., Nonlinear, Soft Matter Phys., 2013, 87, 040501.

16 C. Greco, G. R. Luckhurst and A. Ferrarini, Phys. Chem. Chem. Phys., 2013, 15, 14961-14965.

17 R. J. Mandle, E. J. Davis, C. T. Archbold, S. J. Cowling and J. W. Goodby, J. Mater. Chem. C, 2014, 2, 556-566.

18 C. T. Archbold, E. J. Davis, R. J. Mandle, S. J. Cowling and J. W. Goodby, Soft Matter, 2015, 11, 7547-7557.

19 R. J. Mandle, S. J. Cowling and J. W. Goodby, Phys. Chem. Chem. Phys., 2017, 19, 11429-11435.

20 R. J. Mandle, Chem.-Eur. J., 2017, 23, 8771-8779, DOI: 10.1002/chem.201701167.

21 R. J. Mandle, Soft Matter, 2016, 12, 7883-7901.

22 V. P. Panov, J. K. Vij and G. H. Mehl, Liq. Cryst., 2017, 44, 147-159.

23 T. Ivšić, U. Baumeister, I. Dokli, A. Mikleušević and A. Lesac, Liq. Cryst., 2017, 44, 93-105.

24 C. T. Archbold, J. L. Andrews, R. J. Mandle, S. J. Cowling and J. W. Goodby, Liq. Cryst., 2017, 44, 84-92.

25 J. P. Abberley, S. M. Jansze, R. Walker, D. A. Paterson, P. A. Henderson, A. T. M. Marcelis, J. M. D. Storey and C. T. Imrie, Liq. Cryst., 2017, 44, 68-83.

26 D. A. Paterson, M. Gao, Y. K. Kim, A. Jamali, K. L. Finley, B. Robles-Hernandez, S. Diez-Berart, J. Salud, M. R. de la Fuente, B. A. Timimi, H. Zimmermann, C. Greco, A. Ferrarini, J. M. D. Storey, D. O. Lopez, O. D. Lavrentovich, G. R. Luckhurst and C. T. Imrie, Soft Matter, 2016, 12, 6827-6840.

27 R. J. Mandle, C. C. A. Voll, D. J. Lewis and J. W. Goodby, Liq. Cryst., 2016, 43, 13-21.

28 R. J. Mandle and J. W. Goodby, Chem.-Eur. J., 2016, 22, 93669374.

29 R. J. Mandle and J. W. Goodby, Soft Matter, 2016, 12, 14361443.

30 R. J. Mandle, E. J. Davis, C. C. A. Voll, C. T. Archbold, J. W. Goodby and S. J. Cowling, Liq. Cryst., 2015, 42, 688-703.

31 R. J. Mandle, E. J. Davis, C. T. Archbold, C. C. Voll, J. L. Andrews, S. J. Cowling and J. W. Goodby, Chem.-Eur. J., 2015, 21, 8158-8167.

32 R. J. Mandle, E. J. Davis, S. A. Lobato, C. C. Vol, S. J. Cowling and J. W. Goodby, Phys. Chem. Chem. Phys., 2014, 16, 69076915.

33 R. J. Mandle and J. W. Goodby, ChemPhysChem, 2016, 17, 967-970. 
34 Y. Wang, G. Singh, D. M. Agra-Kooijman, M. Gao, H. K. Bisoyi, C. M. Xue, M. R. Fisch, S. Kumar and Q. Li, CrystEngComm, 2015, 17, 2778-2782.

35 S. M. Jansze, A. Martinez-Felipe, J. M. Storey, A. T. Marcelis and C. T. Imrie, Angew. Chem., Int. Ed. Engl., 2015, 54, 643646.

36 R. J. Mandle and J. W. Goodby, RSC Adv., 2016, 6, 3488534893.

37 R. J. Mandle and J. W. Goodby, Chem.-Eur. J., 2016, 22, 18456-18464.

38 R. J. Mandle, C. T. Archbold, J. P. Sarju, J. L. Andrews and J. W. Goodby, Sci. Rep., 2016, 6.

39 C. T. Archbold, R. J. Mandle, J. L. Andrews, S. J. Cowling and J. W. Goodby, Liq. Cryst., 2017, 1-10, DOI: 10.1080/ 02678292.2017.1360954.

40 R. J. Mandle, M. P. Stevens and J. W. Goodby, Liq. Cryst., 2017, 1-14, DOI: 10.1080/02678292.2017.1343500.

41 F. P. Simpson, R. J. Mandle, J. N. Moore and J. W. Goodby, J. Mater. Chem. C, 2017, 5, 5102-5110.

42 J. W. Goodby, Liq. Cryst., 2017, 1-9, DOI: 10.1080/ 02678292.2017.1347293.

43 V. P. Panov, S. P. Sreenilayam, Y. P. Panarin, J. K. Vij, C. J. Welch and G. H. Mehl, Arxiv:1708:07013, 2017, https://arxiv.org/pdf/1708.07013.pdf.
44 M. J. Frisch, G. W. Trucks, H. B. Schlegel, G. E. Scuseria, M. A. Robb, J. R. Cheeseman, G. Scalmani, V. Barone, B. Mennucci, G. A. Petersson, H. Nakatsuji, M. Caricato, X. Li, H. P. Hratchian, A. F. Izmaylov, J. Bloino, G. Zheng, J. L. Sonnenberg, M. Hada, M. Ehara, K. Toyota, R. Fukuda, J. Hasegawa, M. Ishida, T. Nakajima, Y. Honda, O. Kitao, H. Nakai, T. Vreven, J. A. Montgomery Jr, J. E. Peralta, F. Ogliaro, M. J. Bearpark, J. Heyd, E. N. Brothers, K. N. Kudin, V. N. Staroverov, R. Kobayashi, J. Normand, K. Raghavachari, A. P. Rendell, J. C. Burant, S. S. Iyengar, J. Tomasi, M. Cossi, N. Rega, N. J. Millam, M. Klene, J. E. Knox, J. B. Cross, V. Bakken, C. Adamo, J. Jaramillo, R. Gomperts, R. E. Stratmann, O. Yazyev, A. J. Austin, R. Cammi, C. Pomelli, J. W. Ochterski, R. L. Martin, K. Morokuma, V. G. Zakrzewski, G. A. Voth, P. Salvador, J. J. Dannenberg, S. Dapprich, A. D. Daniels, Ö. Farkas, J. B. Foresman, J. V. Ortiz, J. Cioslowski and D. J. Fox, Gaussian G09 rev e01, 2009.

45 R. J. Mandle, E. J. Davis, C. T. Archbold, S. J. Cowling and J. W. Goodby, J. Mater. Chem. C, 2014, 2, 556-566. 46 V. V. Zuev, Zh. Obshch. Khim., 1997, 67, 1902-1904.

47 C. T. Imrie and G. R. Luckhurst, J. Mater. Chem., 1998, 8, 1339-1343. 